\title{
Characterization of yeast extract co-product bioethanol from empty palm oil bunch
}

\author{
Muhamad Sahlan ${ }^{1,2^{*}}$, Charion Gibreth Hannes ${ }^{1}$, Yanni Sudiyani ${ }^{3}$, Heri Hermansyah ${ }^{1}$ and Anondho Wijanarko ${ }^{1}$ \\ ${ }^{1}$ Department of Chemical Engineering, Faculty of Engineering, Universitas Indonesia, Depok, 16424, Depok, Indonesia \\ ${ }^{2}$ Research Center of Biomedical Engineering, Faculty of Engineering, Universitas Indonesia, Depok, 16424, Indonesia \\ ${ }^{3}$ Chemical Research Centre, Indonesian Institute of Science, Puspiptek area, Serpong, Tangerang Selatan 15314, Indonesia.
}

\begin{abstract}
One of the potential co-product of the manufacture of bioethanol made from oil palm empty fruit bunches are yeasts, which have antioxidant activity. Source of antioxidants can be obtained from vitamins and enzymes. In the characterization study of the antioxidant properties of yeast extract refers to a method performed by Xiong, by varying solvent and extraction time using hot water and ethanol $25 \%$. From the variation of time and solvent extraction will be tested with the GSH content of alloxan method, to obtain the maximum concentration. The results show the isolation of amino acids with a hot solvent, at 15 minutes is better. These results are then carried out the characterization of amino acids with LCMS methods. An amino acid which has antioxidant activity is methionine, using the solvent water and tested methods of abortion LCMS and 3402.91 ppm ethanol with LCMS method implies $4137.002 \mathrm{ppm}$. Characterization of amino acids can then be used as a source of raw materials economic cosmetics worth selling.
\end{abstract}

\section{Introduction}

The use of local isolate of microorganisms that play roles in the fermentation of sugars to ethanol, such as Saccharomyces cerevisiae, which is thermotolerant and ethanol tolerant, are expected could reduce production cost and could solve one of the problems in SSF by providing fermentation microorganisms that are more tolerant to heat and ethanol [1].

Indonesia has produced Empty Fruit Bunch (EFB) waste around 32 million tons per year from wide palm oil plantation [2]. Usually, EFB use for animal feed, while EFB is a potential material for bioethanol synthesis that in a pilot plant production of anhydrous ethanol using oil palm empty fruit bunch [3]. The bioconversion of oil palm empty fruit bunches to bioethanol was set up as a pilot scale unit for development and testing of a process for ethanol production based on enzymatic saccharification. The saccharification using local strains Saccharomyces cerevisiae, at $32^{\circ} \mathrm{C}$ for $48 \mathrm{~h}$ [4]. Formation of ethanol from raw material oil palm empty fruit bunches also produces co-product of bioethanol, Glutathione (GSH), that has a potential activity for the human body as antioxidants. Glutathione (GSH) resulting from intracellular derived from the yeast Saccharomyces cerevisiae was developed in the pharmaceutical and cosmetic industries [5].

The human body has some antioxidant defenses, such as superoxide dismutase (SOD) and glutathione reductase (GSH) which seemed very important. GSH captures free radicals and turns it into GSSG or GSSCy (mixed disulfide with cysteine) and then reduced back to GSH by the enzymatic activity of the GR. GSH protects cells from oxidative stress [6]. Antioxidants help stop the destruction of cells by providing electrons to the free radicals that antioxidants play a role in preventing degenerative diseases [7].

To follow up on this success, we need to study the process of isolation of yeast extract GSH is to get the maximum concentration [8]. In this research, yeast extract extraction will be done with a variety of solvents and extraction time. The isolation process is done with mass 5 $\mathrm{g}$ of yeast extract in $100 \mathrm{~mL}$ of solvent. Solvents used hotwater and $25 \%$ ethanol and then tested with samples of alloxan on solvent conditions and the best extraction time. The aim of this research to characterize the amino acids from yeast extract co-product bioethanol from empty palm oil bunch that have antioxidant activity. Amino acids analyzer were calculated using methods LCMS.

\section{Material and Methods}

\subsection{Materials}

Yeast extract Saccharomyces cerevisiae, $\mathrm{KH}_{2} \mathrm{PO}_{4}-$ $\mathrm{K}_{2} \mathrm{HPO}_{4}$ buffer solution pH 7,6 (Merck), alloxan (SigmaAldrich), HCL solution (Merck), 0,1 M glycine solution (Merck), standard GSH-reduced form (Wako).

*Corresponding author: sahlan@che.ui.ac.id 


\subsection{Extraction yeast extract Saccharomyces cerevisiae}

Saccharomyces cerevisiae yeast extract is obtained from the fermentation of empty palm oil bunch to produce ethanol for 72 hours in LIPI Serpong [4]. Then extraction of the yeast is done by using a beaker glass container and stirred with solvent variations in batch and triple. The extraction process is done with mass $5 \mathrm{~g}$ of yeast extract in $100 \mathrm{~mL}$ of solvent. The solvent used is a hot-water temperature of $95^{\circ} \mathrm{C}$ and with a sampling time of each $3,6,9,12$, and $15 \mathrm{~min}$ and $25 \%$ ethanol at room temperature and sampling time $30,60,90,120$, and 150 minutes. Centrifuge with $4500 / \mathrm{rpm}$ for 10 minutes and the supernatant was obtained. The supernatant is then dried by freeze-drying and solids obtained as $1.9972 \mathrm{~g}$.

\subsection{Antioxidant test (GSH)}

Testing is done by using alloxan [9]. The supernatant of each sample was taken one $\mathrm{mL}$, put in a test tube, added $3.5 \mathrm{~mL}$ of buffer solution $\mathrm{KH}_{2} \mathrm{PO}_{4}-\mathrm{K}_{2} \mathrm{HPO} 4,0.5 \mathrm{ml}$ glycine solution and one $\mathrm{mL}$ of alloxan and reaction occurred for 20 minutes. Absorbance was measured using UV spectrophotometry at a wavelength of $302 \mathrm{~nm}$.

\subsection{Amino Acid characterization}

Samples with hot-water $95^{\circ} \mathrm{C}$ solvent at 15 minutes and $25 \%$ ethanol at room temperature with a time of 150 minutes using LCMS methods. The tools used water Alliance 2695 HPLC Pump Gradient Timetable, X-terra column C8 $3.5 \mathrm{~lm}$, eluent used methanol, water, water + 0.1 HFBA and water +0.1 acetonitrile MFBA. Velocity in the column of $0.150(\mathrm{ml} / \mathrm{min})$ to perform test contained amino acids.

\section{Results and Discussion}

\subsection{Test result antioxidant with water $95^{\circ} \mathrm{C}$ solvent}

The results of measurements of the absorbance values at a wavelength of $302 \mathrm{~nm}$ produces the graph in Fig. 1 below. From the figure, it is seen that with the addition of time then the absorbance value is rising. From the results of measuring the maximum absorbance value maks in the 15 minute is 0.338 . The best time of the solvent extraction of water that can be used to isolate the antioxidant content in yeast extracts. Solvent water is considered good enough to dissolve the antioxidant content in the form of amino acids.

\subsection{Test result antioxidant with ethanol $25 \%$ solvent}

The results of the measurement of absorbance at $302 \mathrm{~nm}$ wavelength shown in Fig. 2. Yeast extraction is done by using ethanol at room temperature conditions. The absorbance values obtained maximum antioxidant content in the 150 minute was 0.2 . When compared to Fig. 1 and Fig. 2 absorbance results obtained are not so significant.

The second use of this solvent is appropriate to isolate antioxidants contained in the yeast extract production byproduct of bioethanol. Antioxidants in the form of amino acid are soluble in water and other polar solvents, but insoluble in non-polar solvents such as diethyl ether or benzene. Amino acids have a great moment dipole and also less acidic than most of the carboxylic acids, and less able than most of the amine [10]. The calibration curves for both absorbances results from solvent water and ethanol $25 \%$ with a standard solution of GSH for 50$200 \mu \mathrm{M}$ concentration variations. Absorbance has optimum value in the range between $0.2-0.8$. From the resulting $\mathrm{r}^{2}$ value, i.e. 0.9904. The isolation of antioxidants by extraction by maceration method has been successful for the presence of the antioxidant in yeast extract bioethanol side product of oil palm empty fruit bunches.

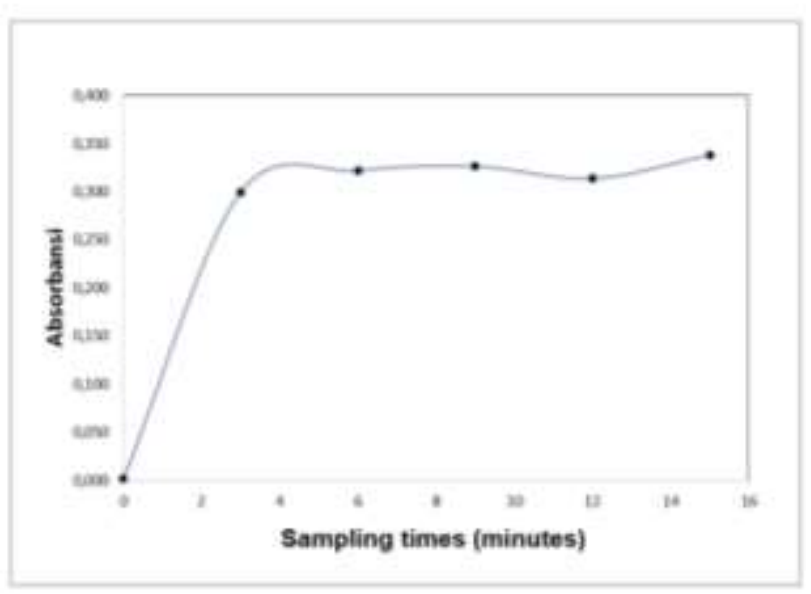

Fig. 1. Antioxidant concentration curve with variable time process solvent extraction using water

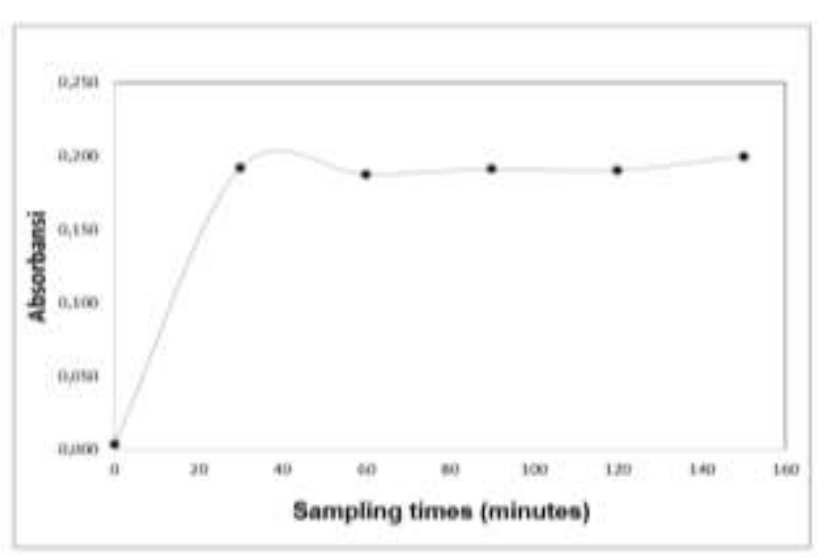

Fig. 2. Antioxidant concentration curve with variable time process solvent extraction using ethanol

\subsection{Amino Acid Analysis}

The results of amino acid analysis using LC-MS method showed higher levels of the amino acid sample of yeast extract solvent of water and ethanol. The total amino acid content is known and has antioxidant content in the samples is shown in Table 1. Judging from the solvent 
used one amino acid levels that act as antioxidants are LMethionine

The amino acid L-Methionine had higher levels of $28.075 \mathrm{mg} / \mathrm{g}$ and $34.698 \mathrm{mg} / \mathrm{g}$. The use of solvents in the extraction has the effect of dissolving ability of amino acids in the sample. The results of the combined detector LCMS MS (mass spectrometer) can be confirmed by the amino acid content of the sample selectively keep solvent used. Mass spectrometry analyzes compounds based on molecular weight and structure of organic compounds. Since each compound generally has a different molecular weight. But from the list for the Methionine amino acids have similar levels.

Table 1. Levels of Amino Acids by LCMS method

\begin{tabular}{lcc}
\hline \multicolumn{1}{c}{ Amino Acid } & $\begin{array}{r}\text { yeast extract } \\
\text { Solvent of water }\end{array}$ & $\begin{array}{c}\text { yeast extract } \\
\text { solvent of ethanol }\end{array}$ \\
\hline L-Alanine & 445,867 & 484,998 \\
L-Arginine & 129,190 & 149,223 \\
L-Aspartic Acid & 154,730 & 219,035 \\
L-Glutamic Acid & 91,740 & 118,140 \\
Glycine & 241,080 & 275,857 \\
L-Histidine & 91,153 & 94,877 \\
L-Isoleucine dan L-Leucine & 105,487 & 105,410 \\
L-Lysine & 336,130 & 271,852 \\
L-Methionine & 28,075 & 34,698 \\
L-Phenylalanine & 66,182 & 68,467 \\
L-Proline & 92,147 & 124,387 \\
L-Serine & 265,607 & 475,608 \\
L-Threonine & 76,538 & 79,277 \\
L-Tyrosine & 82,313 & 84,400 \\
L-Valine & 1196,668 & 1550,773 \\
& $\mathbf{3 4 0 2 , 9 0 7}$ & $\mathbf{4 1 3 7 , 0 0 2}$ \\
\hline
\end{tabular}

Methionine is a sulfur-containing amino acid that is essential in the synthesis cannot be inside the living body so must be obtained from food and inorganic sulfur. Oxidation of methionine as a catcher molecules such as $\mathrm{H}_{2} \mathrm{O}_{2}$ efficient free, hydroxyl radicals, peroxynitrite, chloramine and hypochlorous acid. Methionine residue will act as an endogenous antioxidant, It along with protein susceptibility to oxidation. As a provider of molecular biological functions could be exposed to surface residues methionine very effective as catcher oxidation. There are two surface-exposed methionine residues in interferon or tissue plasminogen three methionine residues. The rate of oxidation of methionine residues in a protein molecule, such as interferon, calmodulin, human parathyroid hormone [11].

\section{Conclusion}

Extraction solvent by maceration using water at a temperature of $95^{\circ} \mathrm{C}$ and $25 \%$ ethanol have isolated antioxidants in the extracted yeast side product of bioethanol made from oil palm empty fruit bunches. The total amino acid contained in the water and ethanol sample solvent by LCMS method were $3402.91 \mathrm{ppm}$ and $4137.002 \mathrm{ppm}$, respectively. Characteristics of amino acids using LC-MS methods provide a more selective compound contained in the till. The amino acid methionine can be used as a reference antioxidant ingredients contained in the by-product of bioethanol to be developed further.

This work is supported by Hibah Publikasi Internasional Terindeks untuk Tugas Akhir Mahasiswa (PITTA) 2018 funded by DRPM Universitas Indonesia (Grant No. 2487/UN2.R3.1/HKP.05.00/2018).

\section{References}

1. Sudiyani, Y. \& Hermiati, E. Utilization of Oil Palm Empty Fruit Bunch ( Opefb) for Bioethanol Production Through Alkali and Dilute Acid Pretreatment and Simultaneous Saccharification and Fermentation. Indones. J. Chem. 10, 261-267 (2010).

2. Hermansyah, H. et al. Effect of aeration and nutrients on Saccharomyces cerevisae cultivation using lignocellulosic hydrolisate from empty fruit bunch. Int. J. Technol. 7, 1110-1118 (2015).

3. Jeon, H. et al. Production of anhydrous ethanol using oil palm empty fruit bunch in a pilot plant. Biomass and Bioenergy 67, (2014).

4. Sudiyani, Y. et al. Utilization of biomass waste empty fruit bunch fiber of palm oil for bioethanol production using pilot - Scale unit. Energy Procedia 32, 31-38 (2013).

5. Kiriyama, K., Hara, K. Y. \& Kondo, A. Oxidized glutathione fermentation using Saccharomyces cerevisiae engineered for glutathione metabolism . Applied Microbiology and Biotechnology 97, 73997404 (2013).

6. Birben, E., Sahiner, U. M., Sackesen, C., Erzurum, S. \& Kalayci, O. Oxidative Stress and Antioxidant Defense. World Allergy Organ. J. 5, 9-19 (2012).

7. Lobo, V., Patil, A., Phatak, A. \& Chandra, N. Free radicals, antioxidants and functional foods: Impact on human health. Pharmacogn. Rev. 4, 118-126 (2010).

8. Xiong, Z.-Q. et al. Efficient extraction of intracellular reduced glutathione from fermentation broth of Saccharomyces cerevisiae by ethanol. Bioresour. Technol. 100, 1011-1014 (2009).

9. Wen, S., Zhang, T. \& Tan, T. Optimization of the amino acid composition in glutathione fermentation. Process Biochem. 40, 3474-3479 (2005).

10. Cornell, W. D. et al. A second generation force field for the simulation of proteins, nucleic acids and organic molecules. J. Am. Chem. Soc. 117, 5179 (1992).

11. Atmaca, G. Antioxidant Effects of SulfurContaining Amino Acids. Yonsei Med J 45, 776-788 (2004). 